\title{
Prevalence of Risks for Obstructive Sleep Apnoea and Its Risk Factors among Adults Attending Government Primary Health Clinics in Kuantan
}

Azwan Faiz Amir Hamzah¹, Mohd Aznan Md Aris ${ }^{1}$, Fa'iza Abdullah¹, Zamzil Amin Asha'ari²

${ }^{1}$ Department of Family Medicine, Kulliyyah of Medicine, International Islamic University Malaysia

${ }^{2}$ Department of Ear, Nose and Throat, Kulliyyah of Medicine, International Islamic University Malaysia

Presenter: Azwan Faiz Amir Hamzah

Introduction: Obstructive sleep apnoea (OSA) is a sleep related breathing disorder with recurrent episodes of apnoea or hypopnoea occurring during sleep. It is associated with increased risk of cardiovascular disease and prone to accidents. However, there is no applicable study that assess the risk for OSA at the primary care level. Objective: This study aims to assess the prevalence of risk for OSA and OSA symptoms and its associated risk factors among adults attending primary care clinics. Materials and method: This cross-sectional study was conducted among 252 adults attending four Klinik Kesihatan in Kuantan, Pahang. The inclusion criteria was adults age 30 years old and above. The exclusion criteria were a known case of Hypothyroidism, Depression and pregnancy. A self-administered validated Malay version of Berlin Questionnaire(BQ) was used to screen for high risk of OSA. The statistical analyses were done using IBM SPSS version 23.0. Results: Majority of the respondents were male (54\%), Malay $(87.7 \%)$, and married $(79.4 \%)$. The prevalence of High Risk for OSA was $32.9 \%$. Among these, $94 \%$ of them presented with snoring and $16.9 \%$ presented with excessive daytime sleepiness. Among male, Malay and married; $48 \%, 32.6 \%$ and $36.5 \%$ respectively was shown to be High Risk for OSA. The risk factors that were found significantly associated with High Risk of OSA includes younger age $(A O R=0.951 \mathrm{Cl}=0.923-0.980)$; higher $\mathrm{BMI}$ classification with obese type $1(\mathrm{AOR}=2.604 \mathrm{Cl}=1.278-5.308)$, obese type $2(\mathrm{AOR}=3.882 \mathrm{Cl}=1.078-13.975)$ and obese type $3(\mathrm{AOR}=6.800 \mathrm{Cl}=1.164-39.717)$; higher neck circumference $(\mathrm{AOR}=1.109 \mathrm{Cl}=1.007-1.221)$; hypertension $(\mathrm{AOR}=2.297 \mathrm{Cl}=1.122-4.702)$; and hypercholestrolaemia $(A O R=2.040 \mathrm{Cl}=1.050-3.965)$. Conclusions: This study shows that nearly one third of the adults attending primary health clinic are at High Risk for OSA and nearly $17 \%$ of them presented with excessive daytime sleepiness. Further study need to be carry out particularly among those of younger age, higher BMI classification, and with co-morbidities. 